zwar die letztere erst kürzlich bekannt geworden. Ich habe die Mittheilungen später übrigens auch im Originale gelesen. Hin m a n kommt auf Grund eigener Untersuchungen, welche solche von W. Frear ${ }^{1}$ ) bestätigen, zu dem Schlusse, dass das Kaliumtetraoxalat sich nicht als Urtitersubstanz eignet, weil seine Darstellung in reinem Zustande grosse Schwierigkeiten darbietet. Ferner hebt er hervor, dass das Salz im trockenen Zustande stark hygroskopisch ist und im wasserhaltigen zum Verwittern neigt.

Was $\mathrm{H}$ inman's Versuche über das Verhalten des Salzes bei $128^{\circ} \mathrm{C}$. anbelangt, so bemerke ich, dass ich selbst keine Versuche über das Trocknen des Tetraoxalates angestellt hatte, sondern die Angabe, das Salz verliere bei $128^{\circ}$ C. sein Krystallwasser, anerkannt guten Werken ${ }^{2}$ ) entnommen hatte, deren eines (siehe Gmelin loc. cit.) sie Berzelius zuschreibt. Hiermit weise ich ausdrücklich jedwede Verantwortlichlieit für jene Angabe zurück, ohne diese übrigens vorläufig kritisiren zu wollen.

Gabinetto di Tecnologia della R. Scuola Superiore di Agricoltura in Portici.

\title{
Neue Ventilpipette.
}

Von

\section{Oscar Bock.}

Der in Fig. 34, S. 433, dargestellte Apparat ist ein Stechheber, beziehungsweise eine Pipette, und kann - wenn nöthig - tarirt werden. Die Grössenverhältnisse können je nach der Verwendungsweise verschieden gewählt werden. Behufs bequemer vollständiger oder theilweiser mechanischer Füllung and Entleerung ist die Pipette mit einem durch den Daumen oder Zeigefinger leicht zu bewegenden Stabventil versehen.

Der eigentliche Pipettenkörper, welcher sich oben und unten kegelförmig verengt, ist durch drei Arme in der Weise mit einem Rohr verbunden, dass zwischen der unteren Rohrmündung und dem Pipetten-

1) U. S. Departement of Agriculture, Division of Chemistry, Bullet. No. 31. Proceedings of the Eigth Annual Convention of the Association of Official Agricultural Chemists, August 13,14 and 15, 1891, p. 131; diese Zeitschrift 33, 456.

2) Gmelin, Handbuch der Chemie, Bd. IV (1848), S.831; Wurtz, Dictionnaire de Chemie pure et appliquée, T. II, S. 680; Watts, Dictionary of Chemistry Edit. 2., Vol. IV (1883), s. 264. 
körper ein freier Raum bleibt. Das Rohr ist an seinem oberen Ende behufs bequemeren Haltens kugelförmig erweitert und dient zur Aufnahme eines an seinem oberen Ende mit einer Kugel, Platte oder sonst einer ähnlichen Einrichtung versehenen Stabes, welcher unten zu einem Ventilkegel ausgebildet ist und in einen entsprechenden in der Pipette befindlichen Ventilsitz passt.

Die Handhabung der Pipette ist eine sehr einfache. Fig. 34. Man erfasst sie mit der rechten Hand am oberen mit Wulst versehenen Theil des Ventilrohres und drückt mit dem Daumen oder Zeigeninger gegen die Verstärkung der Ventilstange, wodurch sich diese vom Ventilsitz hebt. Taucht man darauf den Pipettenkörper in die zu entnehmende Flüssigkeit, so dringt diese in den Pipettenkörper ein, während die verdrängte Luft aus dem geöffneten Ventil entweicht. Befindet sich das gewünschte Flüssigkeitsquantum im Pipettenkörper, so lässt man die Ventilstange auf den Ventilsitz heruntersinken, wodurch ein vollständig luftdichter Abschluss erreicht wird, so dass man sogar im Stande ist, die Pipette in schräge Lage zu bringen, ohne dass ein Flüssigkeitsverlust eintritt. Soll die Flüssigkeit mnu wieder aus der Pipette entfernt werden, so hat man nur nöthig, die Ventilstange wieder mit dem Daumen oder Zeigefinger zu heben, worauf die Flüssigkeit sofort unten abfliesst.

Durch schnelles Heben und Fallenlassen der Ventil-

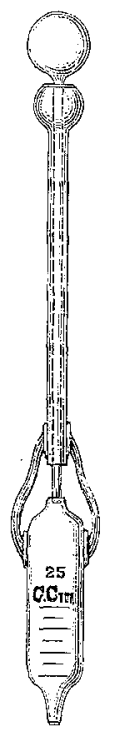
stange kann man ganz nach Belieben auch nur einzelne Tropfen austreten lassen.

Für besondere Zwecke kann der Ventilstab, wenn erforderlich, aus Aluminium oder aus Hartgummi hergestellt werden.

Die vorstehend beschriebene Ventilpipette habe ich zur Eintragung als D. R. G. M. angemeldet.

Kiel, 24. Juni 1895 . 